\title{
Transient Expression of Homologous Hairpin RNA Causes Interference with Plant Virus Infection and Is Overcome by a Virus Encoded Suppressor of Gene Silencing
}

\author{
F. Tenllado, D. Barajas, M. Vargas, F. A. Atencio, P. González-Jara, and J. R. Díaz-Ruíz \\ Departamento de Biología de Plantas, Centro de Investigaciones Biológicas, CSIC, Velázquez 144, 28006 Madrid, Spain
}

Submitted 26 July 2002. Accepted 1 October 2002.

\begin{abstract}
Specific post-transcriptional gene silencing (PTGS) of target genes can be induced in a variety of organisms by providing homologous double-stranded RNA (dsRNA) molecules. In plants, PTGS is part of a defense mechanism against virus infection. We have previously shown and patented that direct delivery to nontransgenic plants of dsRNA derived from viral sequences specifically interfere with virus infection. Here, we show that transient expression of constructs encoding hairpin RNA homologous to a rapidly replicating plant tobamovirus also interferes with virus multiplication in a sequence-dependent manner. A three-day lag period between delivery of hairpin RNA and virus into the same tissues completely block virus infectivity. Several hallmarks characteristic of PTGS were associated with viral interference mediated by hairpin RNA: high level of sequence identity between the hairpin RNA and the target RNA, presence of siRNAs in extracts derived from leaves infiltrated with hairpin RNA, and helper component-proteinase (HC-Pro) of potyviruses, a suppressor of PTGS, overcame interference. No evidence for a mobile silencing suppression signal induced by transient expression of HC-Pro was observed. The approach described here has the potential to be used as a versatile tool for studying the onset of PTGS in cases involving virus infection, in opposition to dsRNA-transgenic plants, which allow primarily for the study of PTGS maintenance.
\end{abstract}

Additional keywords: agroinfiltration, homology-dependent resistance, phleomycin, spacer sequence.

A homology-dependent RNA degradation system seems to operate as a conserved mechanism acting against molecular parasites in most, if not all, eukaryotes (Hammond et al. 2001; Zamore 2002). Double-stranded RNA (dsRNA) is widely recognized as the inducer of these RNA silencing processes in plants (Waterhouse et al. 1998), animals (RNA interference, Fire et al. 1998), and fungi (quelling, Catalanotto et al. 2002). In plants, this process is referred to as post-transcriptional gene silencing (PTGS) and is thought to be involved in a natural line of defense against viral infections (Voinnet 2001). The RNA genome of the invading virus (and any homologous RNA) is targeted and eliminated in a sequence-specific manner when this antiviral mechanism is activated. Most plant viruses have single-stranded RNA genomes that replicate via dsRNA inter-

Corresponding author: J. R. Díaz-Ruíz; Telephone: 34-1-5611800; Fax: 34-1-5627518; E-mail: jrdiazruiz@ cib.csic.es. mediates in the cytoplasm, and this might explain why viruses can be both inducers and targets of gene silencing (Sijen and Kooter 2000). Biochemical analysis of RNA interference in Drosophila melanogaster has shown that dsRNA is recognized by an RNase III-like enzyme (DICER) and cleaved into small RNAs of 21 to 25 nucleotides, called small interfering RNAs (siRNAs) (Hammond et al. 2000). Then, siRNAs are proposed to associate with a second RNase activity (RISC), providing sequence specificity to the complex that targets the cognate single-stranded RNA for destruction (Bernstein et al. 2001). The accumulation of siRNAs has also been detected in natural virus infections in plants (Hamilton and Baulcombe 1999; Szittya et al. 2002), suggesting that mechanisms are conserved across kingdoms. A remarkable feature of RNA silencing is that the process can be induced locally and then spreads to distant parts of the plant via the vasculature (Palauqui et al. 1997; Voinnet et al. 2000). Although the exact nature of the mobile signal is elusive, the sequence specificity of the RNA degradation process indicates that a nucleic acid must be involved (Voinnet 2001). As a response to this defense mechanism, many viruses encode gene-silencing suppressor proteins acting at different points in the PTGS pathway (Mlotshwa et al. 2002; Voinnet et al. 1999). One such suppressor of PTGS, the potyvirus helper component-proteinase (HC-Pro), interferes with a maintenance step of the silenced state (Brigneti et al. 1998; Llave et al. 2000).

RNA silencing is also activated by transgenes expressing either inverted-repeat (IR) structures that produce dsRNA (Chuang and Meyerowitz 2000; Waterhouse et al. 2001) or highly abundant or aberrant transcripts that could be templates for a cellular RNA-dependent RNA polymerase activity (Lipardi et al. 2001). In addition, introduction of dsRNA directly into plant cells triggers PTGS, resulting in the degradation of the cognate mRNA (Schweizer et al. 2000). Transient expression of genes through infiltration of Agrobacterium tumefaciens cultures into leaf tissue (agroinfiltration) has been widely used as a means to deliver RNA silencing inducers and suppressors into transgenic plants that express a silencing reporter gene (Llave et al. 2000; Voinnet et al. 2000). Recently, A. tumefaciens-mediated transient expression has been applied to study RNA silencing in the absence of a stably integrated reporter gene (Johansen and Carrington 2001). It was reported that a highly effective RNA silencing process can be triggered by transient delivery of green fluorescent protein (GFP) dsRNA targeting a codelivered GFP reporter gene. However, it is not known if transient expression of a hairpin RNA could block multiplication and spread of a highly replicating plant 
virus in nontransgenic plants. Furthermore, the combination of both an inducer and a suppressor of PTGS transiently expressed by $A$. tumefaciens could give valuable information about the balance between silencing and suppression of PTGS in the context of a viral infection. We have previously shown that dsRNA derived from viral sequences can interfere with virus infection in a sequence-specific manner by directly delivering in vitro-transcribed dsRNA to leaf cells by mechanical inoculation (Tenllado and Díaz-Ruíz 2001). Here, we have used A. tumefaciens infiltration to deliver a hairpin RNA derived from Pepper mild mottle virus (PMMoV) to study the effect of an RNA silencing inducer on the infectivity of a viral pathogen. This approach could shed light on the initiation stage of PTGS in strategies involving stable integration of transgenes that are able to form a double-stranded RNA structure.

\section{RESULTS}

\section{Transient expression}

\section{of hairpin RNA interferes with virus infection.}

In the present study, we have investigated the silencing potential of constructs designed to generate a hairpin RNA after agroinfiltration for their ability to interfere with a rapidly replicating plant virus. Two key constructs were made in which a hairpin RNA containing PMMoV polymerase gene sequences alone (pBI/IR 54) or fused to the $3^{\prime}$ terminus of the $\beta$-glucuronidase (GUS) gene (pBI/GusIR 54) were transcribed under the control of the cauliflower mosaic virus (CaMV) $35 \mathrm{~S}$ promoter in a binary plasmid vector (pBI121). Since certain IR constructs may be difficult to clone in Escherichia coli, we took advantage of the positive selection conferred by a bacterial gene against the antibiotic phleomycin (Phe). This prokaryotic resistance gene was used as a spacer sequence between the arms of hairpin constructs to improve the stability in $E$. coli and $A$. tumefaciens. The pBI/IR 54 transcript was designed to fold into a stem-loop structure consisting of $977 \mathrm{bp}$ of PMMoV dsRNA and an approximately 500-base hairpin loop containing the bacterial resistance gene. The pBI/GusIR 54 transcript produces the same hairpin RNA with a $5^{\prime}$ region of 1,808 unpaired nucleotides (GUS gene). For comparison, two additional constructs containing duplicated (head-to-head) PMMoV 54-Phe sequences fused to the GUS gene in the sense (Gus[+]ssRNA
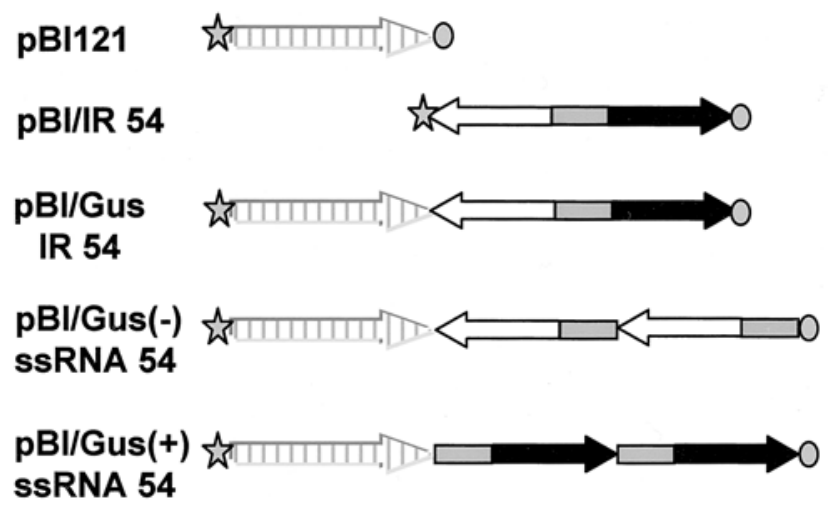

Fig. 1. Schematic representation of constructs used in Agrobacterium tumefaciens-mediated transient expression. The plasmid name for each construct is marked on the left. Constructs used contained the cauliflower mosaic virus $35 \mathrm{~S}$ promoter (gray star) and the 3 '-untranslatable region of nopaline synthase (gray circle). The $\beta$-glucuronidase-coding sequence is represented by a rectangle with vertical stripes; The 977-nt antisense segment of the 54-kDa gene of pepper mild mottle virus (PMMoV) is represented by white arrows pointing to the left; the 977-nt sense segment of the 54-kDa gene of PMMoV is represented by black arrows pointing to the right; and the phleomycin resistance gene is represented by gray rectangles.
54) or antisense (Gus[-]ssRNA 54) orientations were made (Fig. 1).

Two leaves of Nicotiana benthamiana plants were agroinfiltrated with cultures of A. tumefaciens carrying IR 54, GusIR 54, Gus(+)ssRNA 54, or Gus(-)ssRNA 54 constructs. An empty vector construct (pBI121) was also used as a negative control. Northern blot analysis of total RNA extracted from agroinfiltrated leaves at 4 days after infiltration confirmed transient expression of the different constructs, using a specific probe for either the GUS (Fig. 2A) or 54-kDa (data not shown) sequence. A hairpin structure for transiently expressed IR 54 RNA was confirmed by resistance to RNase A under high-salt conditions (data not shown). Transient expression required a Vir+ A. tumefaciens strain, as infection with a Vir- strain containing the GusIR 54 construct did not produce detectable signals (Fig. 2A). At 4 days postinfiltration, plants were inoculated with PMMoV that was directly inoculated on the entire infiltrated leaves. In several independent experiments, plants infiltrated with A. tumefaciens containing the empty vector, Gus(+)ssRNA 54 or Gus(-)ssRNA 54 constructs, displayed disease symptoms in upper leaves at 7 days postinoculation (dpi), whereas all plants (21 plants in eight independent experiments) that were agroinfiltrated with the IR 54 or GusIR 54 constructs were free of symptoms until their life cycles were completed. Northern blot analysis confirmed the visual observations of the accumulation of PMMoV RNA in upper leaves at 14 dpi. PMMoV RNA was not detectable in plants infiltrated with either the GusIR 54 (Fig. 2B) or IR 54 (Fig. 2D) constructs, albeit viral RNA was abundant in plants infiltrated with A. tumefaciens containing the empty vector. Moreover, biologically active virus was absent in homogenates of the upper leaves of plants injected with GusIR 54 or IR 54, as confirmed upon back-inoculation of the local lesion host $N$. tabacum cv. Xanti nc. In contrast, neither Gus(+)ssRNA 54 nor Gus(-)ssRNA 54 RNA expressed by A. tumefaciens interfered with PMMoV accumulation in plants that had received these constructs (Fig. 2B). Furthermore, the interference with PMMoV infection triggered by the PMMoV-derived IR 54 construct was sequencespecific; inoculation of Alfalfa mosaic virus (AMV), an Alfamovirus unrelated to the genus Tobamovirus, on plants injected with IR 54 had no effect on symptom expression, and AMV RNAs accumulation in upper leaves was similar to control plants (Fig. 2C).

To test whether transient IR 54 expression through agroinfiltration could prevent PMMoV infection once the virus had been inoculated on plants, $N$. benthamiana plants were first inoculated with PMMoV and, 24 h later, A. tumefaciens carrying IR 54 or the empty vector was infiltrated into the inoculated leaves or the upper, noninoculated leaves. In both cases, plants displayed typical disease symptoms at $7 \mathrm{dpi}$, and PMMoV RNA accumulated in uppermost leaves similarly to control plants (Fig. 2D). Thus, transient expression of hairpin RNA prior to virus inoculation is required to interfere with $\mathrm{PMMOV}$ infection.

\section{Time dependence of hairpin RNA-mediated interference.}

To evaluate the protective effect against PMMoV infection at different times after delivery of hairpin RNA to plant cells, PMMoV was inoculated on $N$. benthamiana plants simultaneously or from 1 to 7 days after infiltration with either IR 54 or pBI121 in the same leaves. In these experiments, empty vectorinfiltrated plants at any timepoint of the interval tested displayed systemic symptoms at $6 \mathrm{dpi}$. Interestingly, a delay of 3 or more days between agroinfiltration with IR 54 and virus inoculation was able to protect plants against symptom expression. Inoculation with PMMoV simultaneously or 1 to 2 days after inifiltration was unable to protect from virus infection. 
However, symptom expression in plants treated with the 1- to 2-day lag period was delayed by 1 to 2 days as compared with controls, indicating a partial interference with virus infection.

To evaluate the degree of the interference with virus infection conferred by hairpin RNA transient expression on $N$. benthamiana, extracts from the inoculated leaves of those plants were used to back-inoculate the local lesion host, N. tabacum cv. Xanthi nc. Half-leaves were inoculated with plant sap derived from IR 54-infiltrated $N$. benthamiana leaves, and opposite halves were inoculated with vector-infiltrated plant sap at the same dilution $(1: 1,000)$. The number of local lesions elicited in the hypersensitive host were scored, and the mean value of two different trials are shown in Table 1. When IR 54 and virus were introduced simultaneously into plant cells, the number of local lesions was reduced about fourfold. However, a 1- to 2-day lag period between both treatments resulted in a higher reduction of local lesions, consistent with the results observed in the systemic host. Moreover, Northern blot analysis of total RNA extracted from the inoculated $N$. benthamiana leaves showed a dramatic reduction in PMMoV RNA levels in plants that had been agroinfiltrated with IR 541 or 2 days before virus inoculation, as com- pared with pBI121-infiltrated plants (data not shown). PMMoV infectivity was completely abolished when plants were infiltrated with IR 543,4 , or 5 days before virus inoculation, as judged by the absence of lesions in the hypersensitive host. The interference with PMMoV infection in plants infiltrated with IR 54 required expression of the IR 54 construct by a Vir+ A. tumefaciens strain. As shown in Table 1 (4-day interval), tissue injected with a Virstrain containing the IR 54 construct yielded a high number of lesions upon inoculation of the extracts on the local lesion host. Very few local lesions were elicited by extracts derived from plants that had been infiltrated with IR 546 or 7 days before virus inoculation.

Homology-dependent resistance to virus infection is a characteristic feature of PTGS. In order to determine the specificity of the interference conferred by hairpin RNA when the challenging virus and the IR 54 molecules shared a lower degree of homology, an Italian strain of PMMoV (PMMoV-I) and Tobacco mosaic virus strain U1 (TMV-U1) were inoculated on leaves that had been infiltrated 4 days before with either IR 54 or pBI121. PMMoV-I is $93.4 \%$ similar in the region of the 54$\mathrm{kDa}$ gene to the Spanish strain used above, whereas TMV-U1

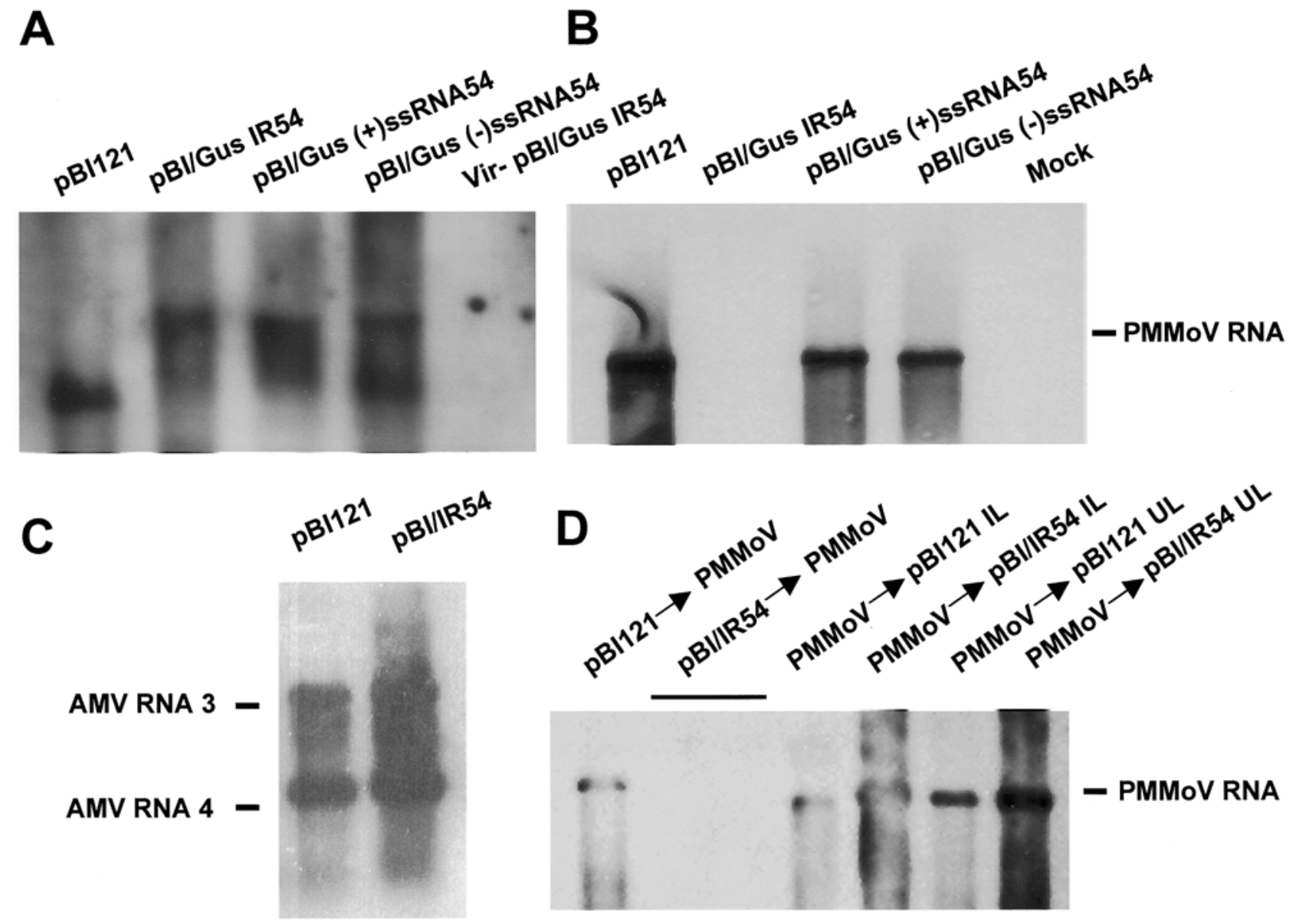

Fig. 2. Specific interference with pepper mild mottle virus (PMMoV) infection by transiently expressed hairpin RNA. A, Two leaves of Nicotiana benthamiana plants were initially infiltrated with Agrobacterium tumefaciens cultures containing pBI121, pBI/GusIR 54, pBI/Gus(+)ssRNA 54, or pBI/Gus(-)ssRNA 54 , as indicated. After 4 days, total RNA was extracted from the infiltrated leaves of representative plants and was subjected to Northern blot analysis to detect $\beta$-glucuronidase (GUS)-related RNAs using a digoxigenin (DIG)-labeled GUS RNA probe. The vir- strain of A. tumefaciens containing pBI/GusIR 54 lacked T-DNA transfer functions and was used as a negative control. Lower smear bands in the three central lines are likely degradation products, since their intensities vary among different experiments. B and $\mathbf{C}$, The infiltrated leaves of the remaining plants were challenge inoculated with either PMMoV or Alfalfa mosaic virus (AMV). After another 14 days, accumulation of B, PMMoV RNA or C, AMV RNAs 3 and 4 was assessed on upper leaves of these plants by Northern blot analysis using DIG-labeled, virus-specific probes. Mock = RNA sample extracted from a noninfiltrated, mock-inoculated plant. D, The same experimental procedure described above was followed for the first three lanes. In the remaining lanes, PMMoV was first inoculated on nontreated leaves. After $24 \mathrm{~h}$, A. tumefaciens cultures carrying pBI121 or pBI/IR 54 were infiltrated into either the inoculated leaves (IL) or the upper, noninoculated leaves (UL), as indicated. Similar amounts $(1 \mu \mathrm{g})$ of RNA samples were fractionated by $1 \%$ agarose gel electrophoresis in B, C, and D. In A, RNA samples $(10 \mu \mathrm{g})$ were fractionated by $0.8 \%$ agarose gel electrophoresis. The positions of PMMoV RNA and AMV RNAs 3 and 4 are indicated in the margins. 
is $73 \%$ similar to PMMoV-S in that region (Alonso et al. 1991). As previously observed for the Spanish strain, transient expression of PMMoV-S-derived IR 54 almost completely blocked PMMoV-I infectivity. $N$. benthamiana plants were devoid of viral symptoms and, furthermore, plant sap from the inoculated leaves of these plants yielded very few local lesions, if any, in the hypersensitive host compared with the control (Table 1). In contrast, plants inoculated with TMV-U1 displayed systemic symptoms at $5 \mathrm{dpi}$, regardless of whether they had been infiltrated with either PMMoV-S-derived IR 54 or pBI121. In agreement with the observed symptoms in these plants, extracts from both the IR 54- and the control-infiltrated plants elicited a similar number of local lesions on N. tabacum cv. Xanthi nc (Table 1).

To determine whether transient IR 54 expression on lower leaves could trigger a systemic antiviral response in upper parts of the plant, PMMoV was inoculated on the upper leaves of $N$. benthamiana plants that had been infiltrated with IR 54 in the lower, fully expanded leaves 7 days before. By 7 dpi, plants inoculated with PMMoV displayed systemic symptoms, regardless of whether they had been infiltrated with IR 54 or the empty vector pBI121. Plant sap from the inoculated leaves of these plants yielded similar numbers of local lesions when inoculated on N. tabacum cv. Xanthi nc (Table 1). Similarly, when half-leaves of $N$. benthamiana plants were infiltrated with the IR 54-expressing construct and the opposite halves were inoculated with PMMoV 7 days later, we did not observe protection against symptom expression on these plants, and the number of local lesions elicited on the hypersensitive host by extracts derived from the inoculated half-leaf was roughly equivalent to those elicited by the control (Table 1). Thus, delivery of virus and A. tumefaciens transiently expressing IR 54 into the same tissue seems necessary to achieve interference with virus infection.

\section{PTGS induced by transient expression of hairpin RNA.}

As an alternative system for examining PTGS-like effects triggered by transient expression of PMMoV hairpin RNA, we used an unrelated viral vector based on Potato virus $X$ (PVX), in which sequences homologous to the PMMoV 54-kDa gene were inserted under the control of a duplicated PVX coat protein $(\mathrm{CP})$ promoter $(\mathrm{PVX} / 54)$. It was anticipated that the chimeric virus would not accumulate in plants if viral resistance elicited by transient expression of PMMoV hairpin RNA was based on PTGS (English et al. 1996; Szittya et al. 2002). First, plants were infiltrated with $A$. tumefaciens cultures carrying IR 54 or the empty vector (pBI121). At 4 days postinfiltration, plants were challenge-inoculated with PVX or PVX/54 on the injected leaves. The first systemic symptoms appeared at $7 \mathrm{dpi}$ on plants inoculated with PVX that had been infiltrated with IR 54 or pBI121. By $11 \mathrm{dpi}$, mosaic symptoms were displayed by PVX/54-inoculated plants that had been infiltrated with pBI121. In contrast, plants challenge-inoculated with PVX/54 that had been previously infiltrated with IR 54 remained symptomless throughout the entire testing period ( 2 months). Northern blot analysis of RNA samples taken from systemic leaves at 15 dpi showed that PVX/54 accumulated in plants that had been infiltrated with pBI121 at comparable levels to PVXinoculated plants that had been infiltrated with IR 54 (Fig. 3A) or pBI121 (data not shown). In agreement with the lack of symptoms, neither PVX/54 nor any naturally occurring derivatives with the deleted 54-kDa insert were detected in the upper leaves of plants infiltrated with IR 54 in two independent experiments carried out with RNAs from different transcription reactions. These results suggest that interference with virus infection conferred by transient expression of PMMoV hairpin RNA may be due to the activation of PTGS.
To further test whether interference with PMMoV conferred by transient expression of hairpin RNA was attributable to PTGS, the small RNA fraction was extracted from noninoculated, A. tumefaciens-infiltrated leaves and analyzed by Northern blot hybridization with a radiolabeled probe specific for the PMMoV 54-kDa sequence. Small RNA species characteristic of PTGS were detected in plants that had been infiltrated 4 days before with either IR 54 or GusIR 54 but were absent in pBI121-infiltrated plants (Fig. 3B).

\section{Suppression of hairpin RNA-mediated interference by Plum pox virus HC-Pro.}

In the last years, it has been demonstrated that HC-Pro of potyviruses is a suppressor of PTGS (Brigneti et al. 1998; Kasschau and Carrington 1998). Moreover, RNA silencing triggered by a double-stranded GFP transcript transiently expressed by agroinfiltration was partially inhibited by HC-Pro of Tobacco etch virus (TEV). To study this effect, the silencing-inducing A. tumefaciens was infiltrated together with a second culture of A. tumefaciens containing a binary vector that allowed expression of the TEV HC-Pro (Johansen and Carrington 2001). We used this coinfiltration assay to test the ability of HC-Pro of potyviruses to block the resistance against a highly replicating plant virus conferred by transient expression of a hairpin RNA homologous to the virus. Therefore, we cloned a translatable version of the HC-Pro of Plum pox virus (PPV) into pBI121 (pBI/HCT). We assumed that the HC-Pro of PPV could behave as a suppressor of PTGS, since it has been previously shown to be involved in viral synergism with PVX in $N$. benthamiana (Sáenz et al. 2002; P. González-Jara, unpublished data), a phenomenon closely related to the silencing suppressor activity of HC-Pro in other potyviruses. Equivalent volumes of A. tumefaciens culture harboring $\mathrm{pBI} / \mathrm{HCT}$ and A. tumefaciens culture containing either the empty vector or PMMoV IR 54 were mixed and infiltrated into leaves of $N$. benthamiana plants. As controls, plants were infiltrated with A. tumefaciens mixtures carrying IR 54 plus the empty vector or IR 54 plus $\mathrm{pBI} / \mathrm{HCNT}$. The $\mathrm{pBI} / \mathrm{HCNT}$ construct contains a nontranslatable version of the HC-Pro of PPV. At 4 days postinfiltration, plants were inoculated with PMMoV, which was directly inoculated on the entire infiltrated leaves. As expected, plants infiltrated with an A. tumefaciens mixture containing $\mathrm{pBI} / \mathrm{HCT}$ and the empty vector displayed disease symptoms in upper leaves at $7 \mathrm{dpi}$, whereas plants that were infiltrated with the mixture containing either IR 54 and pBI/HCNT (Fig. 4A) or IR 54 and the empty vector (data not shown) were free of symptoms until their life cycles were completed. These results indicate that the coinfiltration assay itself does not affect the plant resistance response to virus infection elicited by expression of IR 54. Interestingly, plants infiltrated with the mixture containing $\mathrm{pBI} / \mathrm{HCT}$ and IR 54 became infected with PMMoV at the same postinoculation time as controls, indicating that the interference with PMMoV infection triggered by the IR 54 construct was suppressed by the transiently expressed HC-Pro of PPV (Fig. 4A). This result was obtained in two independent experiments involving a total of 10 plants. Transient HC-Pro expression in plants infiltrated with the mixture pBI/HCT plus IR 54 was confirmed by immunoblot analysis of total proteins extracted from the infiltrated and inoculated leaves at $7 \mathrm{dpi}$, using a PPV HC-Pro-specific polyclonal antiserum (Fig. 4B). The CP of PMMoV was further detected in the same leaves with a PMMoV-specific antiserum (Fig. 4C). However, accumulation of $\mathrm{PMMoV} \mathrm{CP}$ was reduced compared to plants infiltrated with the mixture $\mathrm{pBI} / \mathrm{HCT}$ plus the empty vector. Northern blot analysis of total RNA extracted from upper leaves at 20 dpi confirmed the visual symptoms (Fig. 4D). PMMoV RNA accumulated at high levels in plants infiltrated with $A$. tumefaciens containing $\mathrm{pBI} / \mathrm{HCT}$ plus the empty vector 
and $\mathrm{pBI} / \mathrm{HCT}$ plus IR 54. As expected, PMMoV RNA was not detectable in plants infiltrated with the mixture $\mathrm{pBI} / \mathrm{HCNT}$ plus IR 54.

The suppression of PTGS by HC-Pro could potentially be mediated, at least in part, by the activation of a pathway that transmits and amplifies the inhibition of silencing to other parts of the plant by a mechanism similar to the trafficking of endogenous proteins and their transcripts between cells and through the phloem (Jorgensen et al. 1998). Hence, it has been demonstrated that HC-Pro is able to move cell to cell through plasmodesmata (Rojas et al. 1997). To determine if HC-Pro suppression of hairpin-mediated interference with $\mathrm{PMMoV}$ infection was translocated across the phloem, we devised a set of experiments involving the sequential infiltration of plants in different leaves with single A. tumefaciens cultures (Fig. 5A). Two opposite leaves were injected with A. tumefaciens carrying either $\mathrm{pBI} / \mathrm{HCT}$ or the empty vector. After 7 days, plants were infiltrated with any of the four combinations with $A$. tumefaciens harboring IR 54 or the empty vector in upper, newly developed leaves of the previously infiltrated plants. After another 4 days, PMMoV was inoculated on the uppermost, infiltrated leaves and susceptibility to virus infection was assessed by both visual observation of systemic symptoms and Northern blot analysis. By $11 \mathrm{dpi}$, all plants that had been infiltrated with the empty vector in the secondary infiltrations displayed viral symptoms, regardless of whether they had been infiltrated with either $\mathrm{pBI} / \mathrm{HCT}$ or $\mathrm{pBI} 121$ in the primary infiltrations. Interestingly, plants that had been injected with $\mathrm{pBI} / \mathrm{HCT}$ in the primary infiltration and then with IR 54 in the secondary infiltration did not show disease symptoms. This lack of symptom expression also occurred in plants infiltrated with the combination of the empty vector followed by IR 54 . Accordingly, RNA analysis of samples extracted from the inoculated leaves confirmed the accumulation of $\mathrm{PMMoV}$ RNA in plants displaying viral symptoms (Fig. 5B). In contrast, viral RNA was not detected in plants that had been infiltrated with the combination $\mathrm{pBI} / \mathrm{HCT}$ followed by IR 54, suggesting that local expression of PPV HC-Pro does not induce a mobile silencing suppression signal acting in upper parts of the plant. An alternative explanation is that movement of HC-Pro, or any derivative of the PTGS suppression pathway, is not sufficiently rapid to attain functional levels in the upper leaves of plants that have been infiltrated with HC-Pro 7 days before.

\section{DISCUSSION}

We have shown that A. tumefaciens-mediated transient expression of homologous hairpin RNA blocks multiplication and spread of a rapidly replicating plant virus in a sequence-dependent manner in nontransgenic plants. Recently, Johansen and Carrington (2001) reported that RNA silencing can be triggered by transient expression of dsRNA GFP targeting a codelivered GFP reporter gene. Our work extends these findings on the use of transiently-expressed hairpin RNA to interfere with plant virus infection. This interference was achieved by a hairpin RNA with perfectly matched arms (PMMoV IR 54), but also by a hairpin RNA with a $5^{\prime}$ region of 1,800 unpaired nucleotides (GusIR 54). dsRNA is considered as a strong inducer of PTGS, leading to the production of siRNAs that are incorporated into the nuclease complex (RISC) responsible for the degradation of the target RNA (Hammond et al. 2000). In that sense, we propose that the transiently expressed hairpin RNA activates the PTGS machinery in cells where A. tumefaciens is actively expressing its T-DNA. Thus, the invading virus containing sequences homologous to the stem of the hairpin RNA is recognized by the defense mechanism, which then leads to the elimination of the viral RNA. In fact, we have found several features associated with transient expression of hairpin RNA that are hallmarks of PTGS. First, the interference with virus infection exhibited by hairpin RNA was dependent on a high level of sequence identity between the hairpin RNA and the target RNA, as inoculation of PMMoV IR-infiltrated plants with an unrelated virus, AMV or TMV (73\% identity), did not affect virus infection, whereas infection by PMMoV-I, which shares $93 \%$ sequence identity with the IR 54 sequence, was protected against. Further evidence for a homology-dependent type of resistance came from the observation that plants infiltrated with IR 54 were resistant to a vector of PVX carrying sequences homologous to the PMMoV hairpin RNA; however, they were susceptible to PVX (English et al. 1996; Szittya et al. 2002). Second, siRNAs of two size classes were found in extracts from IR 54-infiltrated tissue. These siRNAs are consistently associated with an activated PTGS status (Hamilton and Baulcombe 1999). Finally, the interference with PMMoV infection triggered by IR 54 was overcome by HC-Pro of potyviruses, a well-known suppressor of PTGS in plants (Voinnet 2001). The HC-Pro of PPV has not been directly demonstrated to suppress PTGS induced by transgenes. However, it has been shown to induce synergism with PVX in $N$. benthamiana (Sáenz et al. 2002; P. González-Jara, unpublished data), which, in fact, supports its capability to suppress PTGS induced by transiently expressed IR 54 as shown in this work. Moreover, infection by turnip mosaic potyvirus has been shown to inhibit silencing induced by an IR transgene (Béclin et al. 2002), demonstrating that HC-Pro of potyviruses suppresses PTGS induced by transiently expressed or integrated IR transgenes.

Table 1. Time-dependent interference with Pepper mild mottle virus (PMMoV) by Agrobacterium tumefaciens-mediated transient expression of PMMoV $54-\mathrm{kDa}$ IR

\begin{tabular}{|c|c|c|c|c|c|c|c|c|}
\hline \multirow[b]{2}{*}{ Inocula } & \multicolumn{8}{|c|}{ No. of lesions from PBI121- versus pBI/IR-infiltrated leaves } \\
\hline & O days & 1 & 2 & 3 & 4 & 5 & 6 & 7 \\
\hline PMMoV-S & $222 / 59^{\mathrm{a}}$ & $82 / 1.5$ & $102 / 2.5$ & $88 / 0$ & $112 / 0^{\mathrm{b}}$ & $69 / 0$ & $46 / 2$ & $38 / 1$ \\
\hline PMMoV-I & $\ldots$ & $\ldots$ & $\ldots$ & $\ldots$ & $60 / 1$ & $\ldots$ & $\ldots$ & $\ldots$ \\
\hline TMV-U1 & $\ldots$ & $\ldots$ & $\ldots$ & $\ldots$ & $>200 />200$ & $\ldots$ & $\ldots$ & $\ldots$ \\
\hline PMMoV-S & $\ldots$ & $\ldots$ & $\ldots$ & $\ldots$ & $\ldots$ & $\ldots$ & $\ldots$ & $51 / 61$ \\
\hline PMMoV-S & $\ldots$ & $\ldots$ & $\ldots$ & $\ldots$ & $\ldots$ & $\ldots$ & $\ldots$ & $32 / 33$ \\
\hline
\end{tabular}

a Values are the number of local lesions elicited by Nicotiana benthamiana plant extracts inoculated with the indicated viruses on $N$. tabacum cv. Xanthi nc. Leaves of $N$. benthamiana plants were initially infiltrated with A. tumefaciens cultures carrying the PMMoV 54-kDa IR-expressing vector (IR) or the vector alone (pBI121). After the indicated interval (between 0 to 7 days), the agroinfiltrated leaves of these plants were challenge-inoculated with either PMMoV-S $(10 \mu \mathrm{g} / \mathrm{ml})$, PMMoV-I $(10 \mu \mathrm{g} / \mathrm{ml})$, or TMV-U1 $(5 \mu \mathrm{g} / \mathrm{ml})$. After another 6 days, extracts from these leaves, diluted 1:1,000, were assessed on opposite halfleaves of $N$. tabacum cv. Xanthi nc. Data are the average number of necrotic local lesions per inoculated half-leaf in two different trials counted 5 days postinoculation. The values given in the numerator are from pBI121-infiltrated leaves, and the values in the denominator are from $\mathrm{pBI} / \mathrm{IR}$ 54-infiltrated leaves.

b An A. tumefaciens vir- strain carrying the PMMoV 54-kDa IR was used instead of pBI121.

c PMMoV-S was inoculated on upper, nonagroinfiltrated leaves.

${ }^{\mathrm{d}}$ A. tumefaciens cultures were infiltrated on half-leaves. PMMoV-S was inoculated on the opposite half-leaves. 
A

Agroinfiltration

IR54

pBI121

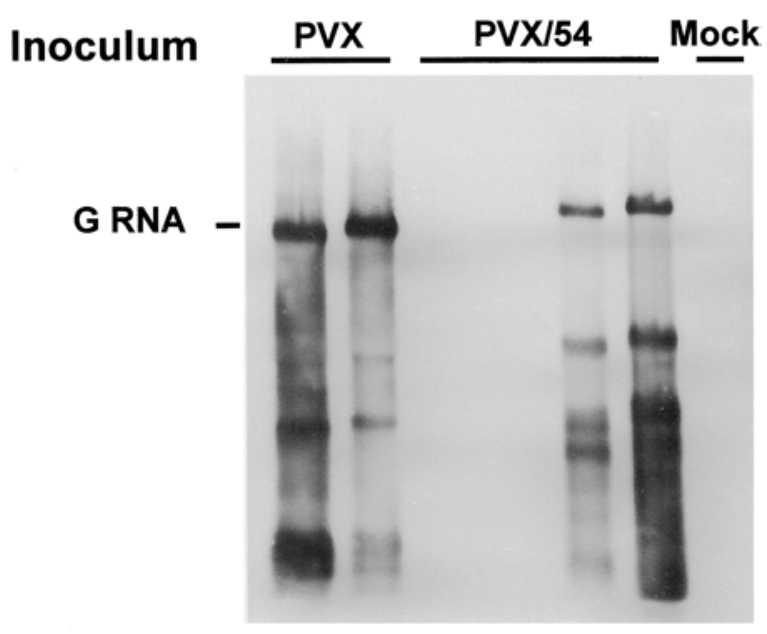

B
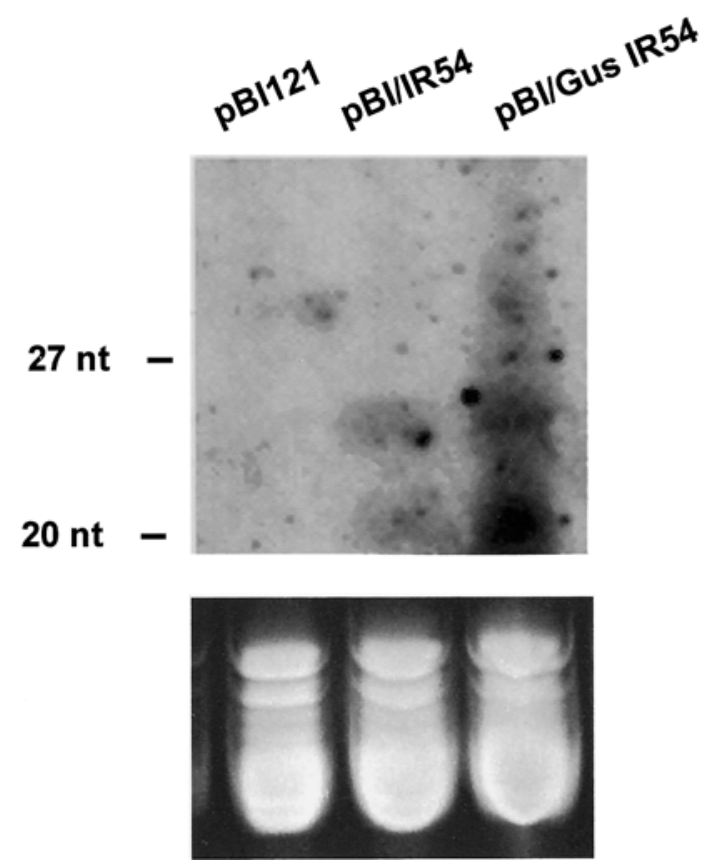

Fig. 3. Induction of post-transcriptional gene silencing by transient expression of pepper mild mottle virus hairpin RNA. A, Northern blot analysis of total RNA extracted from Nicotiana benthamiana plants infiltrated with Agrobacterium tumefciens containing pBI121 or pBI/IR 54 and challenge-inoculated with either Potato virus $X$ (PVX) or PVX/54 4 days later, as indicated. Samples were taken from upper leaves at 15 days after the challenge-inoculation. Mock $=$ RNA sample extracted from a noninfiltrated, mock-inoculated plant. Similar amounts $(1 \mu \mathrm{g})$ of RNA samples were fractionated by $0.8 \%$ agarose gel electrophoresis, and the filter was hybridized with a digoxigenin (DIG)-labeled RNA probe specific for PVX. The position of PVX genomic RNA (G RNA) is indicated in the margin. The lower bands are the 3'-proximal subgenomic RNAs. B, Northern blot analysis of low molecular weight RNAs shows the accumulation of siRNAs in pBI/IR 54- and pBI/GusIR 54-infiltrated leaves. Samples were taken 4 days after infiltration. The blot was hybridized with a ${ }^{32} \mathrm{P}$-labeled cDNA 54-kDa probe. Equivalent loading of samples was shown by staining the gel with ethidium bromide before transfer. The mobilities of oligodeoxynucleotides of the indicated length are shown to the left.
Previously, it was shown that the HC-Pro of TEV partially inhibits PTGS induced by a transiently expressed dsGFP construct at early stages, although RNA silencing eventually occurred at later stages (Johansen and Carrington 2001). The apparent discrepancy with our results could be explained in the context of virus infection. Replication of a few virus particles allowed by the HC-Pro suppressor activity is sufficient to partially overcome the inhibitory effect of IR 54 in the inoculated leaves, so that the virus spreads throughout the plant. Thus, in fact, the levels of PMMoV CP in inoculated leaves that had been infiltrated with IR 54 plus HC-Pro was lower than in tissues injected with a mixture lacking IR 54 (HC-Pro plus the empty vector). Similarly, it was shown that transient expression of a functional GFP mRNA acted as a weak inducer of PTGS against its own expression (Johansen and Carrington 2001). In contrast, PMMoV-derived single-stranded RNAs of either sense or antisense polarity had no effect on virus infection. It is possible that weak inducers activate PTGS more slowly than strong inducers so that, once PMMoV initiates replication, it is able to evade the ongoing defense mechanism.

Interference with PMMoV infection triggered by hairpin RNA was investigated by inoculating the virus at different times after delivery of IR 54 to plant leaves. Although the simultaneous delivery of virus and IR 54 reduced fourfold the number of infectious particles in the inoculated leaves (as bioassayed in a local lesion host) a 3- to 7-day interval between both treatments was required to completely block virus infectivity and to prevent systemic infection on plants. This probably reflects the time required for $A$. tumefaciens to express the T-DNA (maximum at $48 \mathrm{~h}$ postinfiltration; Kasschau and Carrington 2001). However, delivery of virus and hairpin RNA into the same tissues seems necessary, because IR-infiltrated plants challenged with PMMoV in upper, noninfiltrated leaves became infected. It has been reported that a nuclear component, transgene or endogenous gene, homologous to the target RNA is required for propagation and amplification of the systemic silencing signal (Palauqui and Balzergue 1999). The absence of such a component in our nontransgenic system, together with the failure of $A$. tumefaciens to efficiently move for long distances, precludes spreading of RNA silencing to the upper part of the plant.

It is generally accepted that dsRNA produced during replication of RNA viruses triggers induction of the PTGS antiviral defense mechanism in plants, at least under certain circumstances (Dalmay et al. 2000; Voinnet et al. 2000). Interestingly, transient expression of hairpin RNA homologous to PMMoV interferes with virus infection, whereas dsRNA is a natural intermediate in tobamovirus replication (Palukaitis and Zaitlin 1986) unable to trigger an associated virus-induced gene silencing phenomenon. While virus replication might be associated with specific subcellular structures in the case of transient expression by A. tumefaciens, the plant would be able to detect hairpin RNA, activating the PTGS machinery that targets viral RNA for destruction. Alternatively, many plant viruses, including tobamoviruses (Voinnet et al 1999), encode PTGS suppressors that could prevent a silenced status in the plant, even in the presence of high levels of viral dsRNA.

Unequivocal evidence exists that RNA silencing can be transmitted throughout plants by a mobile systemic signal (Mlotshwa et al. 2002). On the other hand, several plant viral silencing suppressors are known to affect systemic signaling of silencing (Brigneti et al. 1998; Voinnet et al. 2000), in agreement with the notion that systemic infection by a virus requires diminishing the antiviral silencing defense response. The previous findings allow us to propose a model in which silencing suppressors, or derivatives of the PTGS suppression pathway, act non-cell-autonomously, moving from 
infected to uninfected parts of the plant, preventing the spread of virus infection. We have tested such a model using the HC-Pro of potyviruses and hairpin-mediated interference with PMMoV infection. No evidence for a mobile silencing suppression signal induced by HC-Pro of PPV was observed in our system. HC-Pro transiently expressed in lower leaves failed to suppress the inhibitory effect on PMMoV replication triggered by infiltration of IR 54 in upper leaves. However, this result does not completely rule out the involvement of a mobile silencing suppression signal in natural potyvirus infection. For instance, PTGS suppression signaling to distal parts of the plant may require the accumulation of a threshold level of HC-Pro or of any other potyviral protein. P1 proteinase of TEV has been shown to enhance suppression of virus-induced gene silencing by HC-Pro (Anandalakshmi et al. 1998). Alternatively, defense-related chitinase and $\beta-1,3$ glucanase host genes have been reported to be strongly induced by infiltration of $A$. tumefaciens cultures into leaves (Schöb et al. 1997). This response could somehow interfere with the PTGS suppression signaling pathway.

The hairpin-dependent interference with PMMoV infection observed here with transiently expressed PMMoV IR 54 is fully consistent with several studies using transgenic plants capable of expressing double-stranded or single-stranded self-complementary RNA that are immune to potato virus $\mathrm{Y}$ infection through a PTGS mechanism (Smith et al. 2000; Waterhouse et al. 1998). IR constructs are unstable and undergo genetic rearrangements in E. coli (Collins 1981); therefore, we employed a spacer sequence conferring resistance against the antibiotic Phe. Hairpin RNAs are expected to be more readily produced and to remain stable by the use of a selectable marker, thus providing a convenient alternative approach to the use of noncoding spacers.

In conclusion, our work expands the applications of the transient RNA silencing assay described by others to the study of inducers and suppressors of PTGS in the background of a virus infection. Although described here for $\mathrm{PMMoV}$, it is reasonable to expect that many plant RNA viruses will be inhibited by their homologous hairpin RNAs. This approach provides a potential tool to study the onset of PTGS in viral infection, in contrast to dsRNA-transgenic plants which primarily allow the study of PTGS maintenance. The available evidence indicates that expression obtained by injecting plant cells with A. tumefaciens is pri-
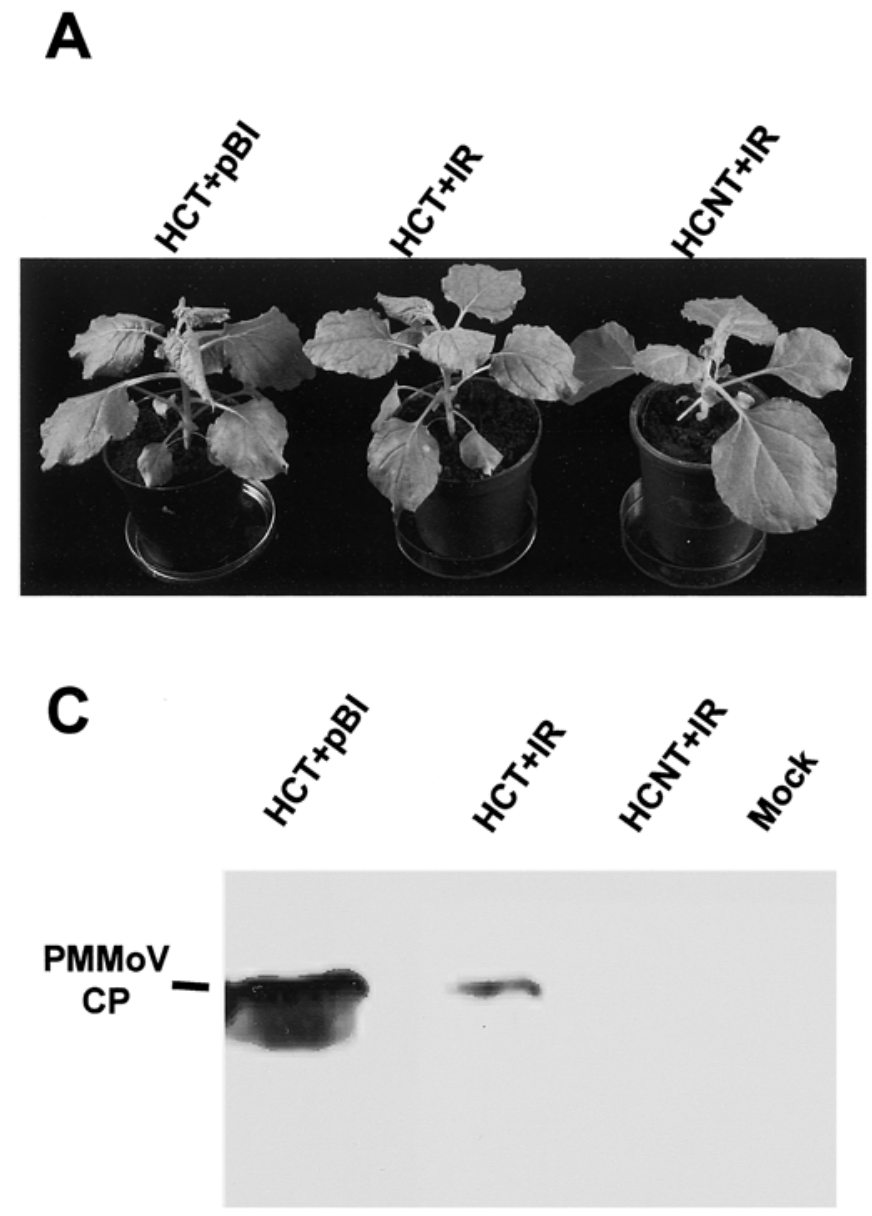

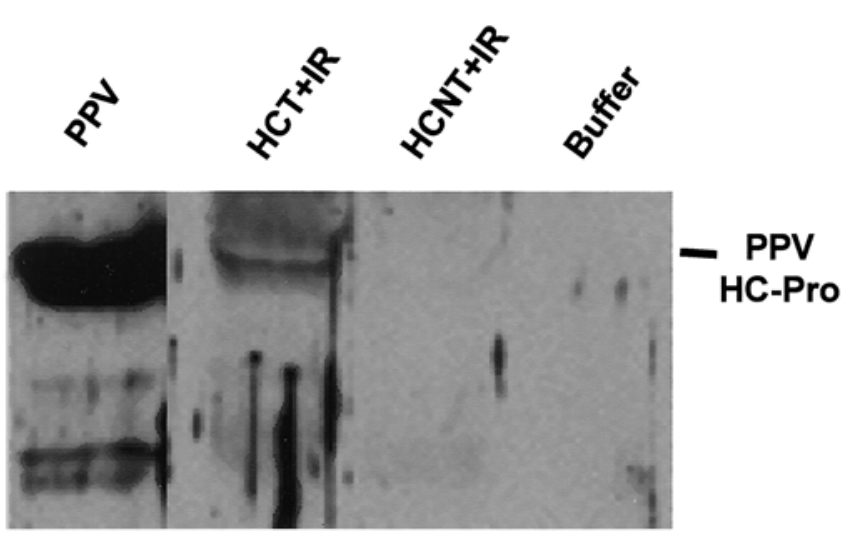

B

D
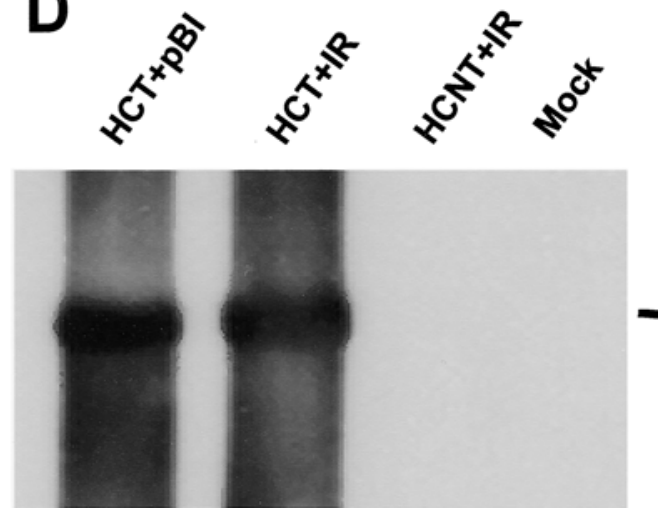

PMMoV

RNA

Fig. 4. Interference with pepper mild mottle virus (PMMoV) infection triggered by IR 54 is suppressed by helper component-proteinase (HC-Pro) of Plum pox virus (PPV). A, Two leaves of Nicotiana benthamiana plants were initially infiltrated with combinations of Agrobacterium tumefaciens cultures containing $\mathrm{pBI} / \mathrm{HCT}$ plus the empty vector (pBI), pBI/HCT plus pBI/IR 54, and pBI/HCNT plus pBI/IR 54, as indicated. After 4 days, the infiltrated leaves of these plants were challenge-inoculated with PMMoV. After another 7 days, plants displaying disease symptoms (pBI/HCT plus the empty vector and $\mathrm{pBI} / \mathrm{HCT}$ plus $\mathrm{pBI} / \mathrm{IR} 54$ ) or showing resistance to virus infection (pBI/HCNT plus pBI/IR 54) were photographed. B, Accumulation of PPV HC-Pro on extracts taken from inoculated leaves of these plants at 7 dpi was assessed by immunoblot analysis using anti-HC-Pro sera. $\mathrm{PPV}=$ extract from PPV-infected plant diluted 1:10 in extract from a healthy plant. Buffer = extract from a plant infiltrated with infiltration buffer. C, Accumulation of PMMoV coat protein (CP) was assessed on the same extracts used in B by immunoblot analysis using anti-PMMoV sera. Mock = extract from a buffer-infiltrated, mock-inoculated plant. D, Accumulation of PMMoV RNA was assessed on upper leaves of these plants at 20 dpi by Northern blot analysis using a digoxigenin (DIG)-labeled 54-kDa probe. Mock = RNA sample extracted from a buffer-infiltrated, mock-inoculated plant. Similar amounts $(1 \mu \mathrm{g})$ of RNA samples were fractionated by $1 \%$ agarose gel electrophoresis. The positions of PPV HC-Pro, PMMoV CP, and PMMoV RNA are indicated in the margins. 
marily due to transcription of ectopic T-DNA, rather than the generation of stably integrated transgenes (Sonti et al. 1995). In previous studies, HC-Pro was shown to interfere with a maintenance step of the silenced state (Brigneti et al. 1998; Llave et al. 2000). Our coinfiltration assays, in which expression of HC-Pro occurs at the same time as initiation of silencing by IR 54, suggest that HC-Pro also interferes with the initiation of PTGS. This approach will be useful in analyzing structural determinants of hairpin RNA required to promote efficient target RNA degradation in plants, as has been determined in Drosophila (Zamore 2002).
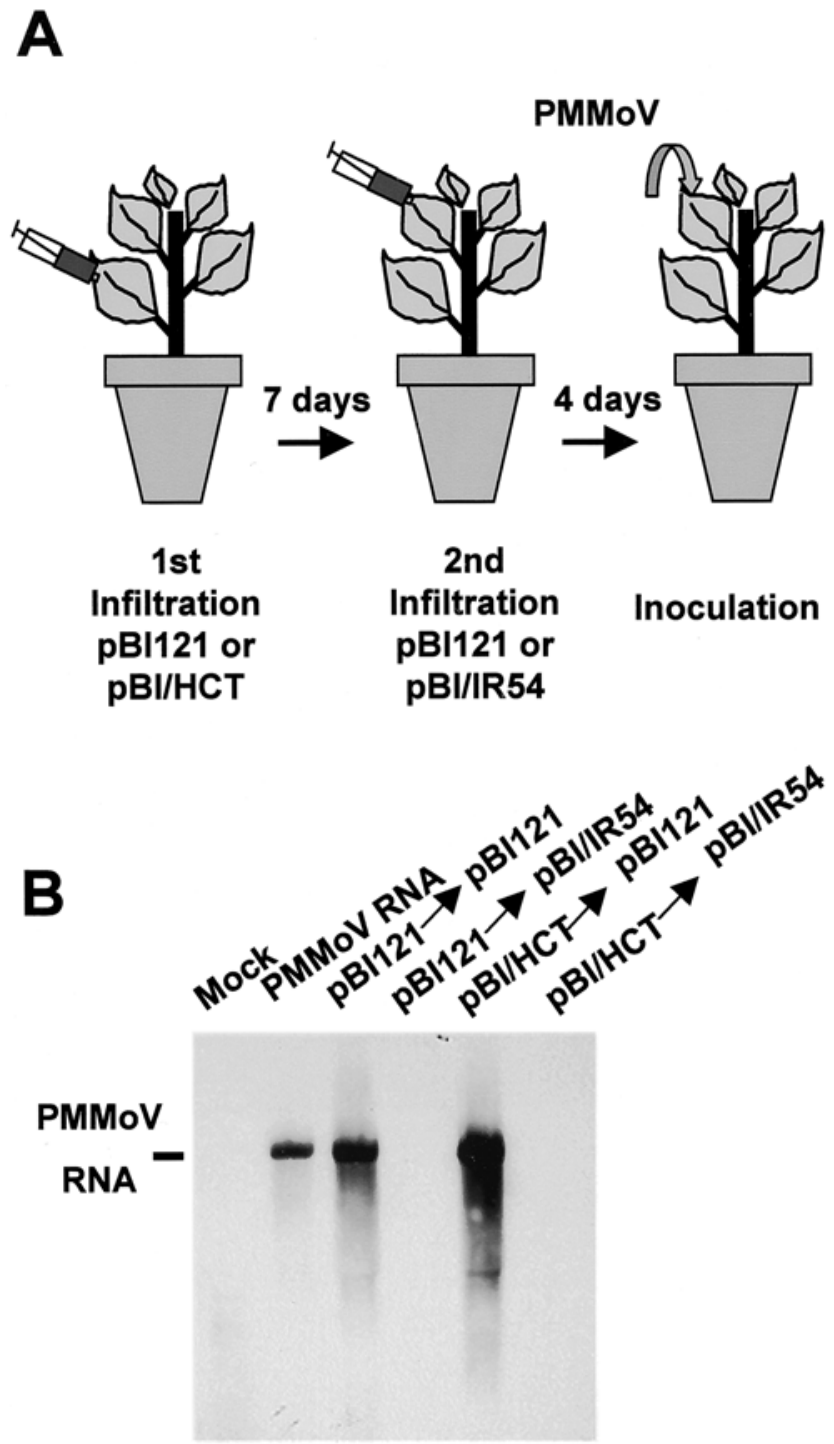

Fig. 5. Plum pox virus (PPV) helper component-proteinase (HC-Pro) expressed in lower leaves does not suppress hairpin-mediated interference with pepper mild mottle virus (PMMoV) infection in upper leaves. A, Schematic representation of the experimental procedure. Two lower, opposite leaves of Nicotiana benthamiana plants were first infiltrated with Agrobacterium tumefaciens containing either pBI121 or $\mathrm{pBI} / \mathrm{HCT}$. After 7 days, upper leaves of these plants were infiltrated in all the combinations with A. tumefaciens containing either pBI121 or $\mathrm{pBI} / \mathrm{IR}$ 54. Four days later, PMMoV was inoculated on the uppermost, infiltrated leaves. B, Northern blot analysis of total RNA extracted from the inoculated leaves of plants challenge-inoculated with PMMoV at 15 days postinoculation. Mock $=$ RNA sample extracted from a buffer-infiltrated, mock-inoculated plant. PMMoV RNA = purified PMMoV RNA (10 ng) used as a control. Similar amounts $(1 \mu \mathrm{g})$ of RNA samples were fractionated by $1 \%$ agarose gel electrophoresis, and the filter was hybridized with a digoxigenin-labeled 54-kDa RNA probe.

\section{MATERIALS AND METHODS}

Plasmid constructs.

To prepare a hairpin RNA corresponding to part of the $54-\mathrm{kDa}$ gene (the readthrough portion of the $183-\mathrm{kDa}$ replicase gene) (Palukaitis and Zaitlin 1986) of PMMoV, the pGEM-T Easy cloning vector (Promega, Barcelona, Spain) was modified by sequential insertion of three genetic cassettes. In a first cloning step, the SalI-SacI fragment from pT3T7/54kDa (Tenllado et al. 1995) spanning from nucleotides 3,411 to 4,388 in PMMoV RNA was cloned in the sense orientation into SalI-SacIdigested pGEM-T to generate pGEM/54. An intermediate construct was made by cloning the approximately 500-bp ThaIHaeIII DNA fragment harboring the phleomycin (Phe) resistance gene and regulatory regions from plasmid pUB110 (Bravo and Alonso 1990) into HindII-cleaved pUC18 to generate pCB278. Next, the EcoRI-PstI fragment from pCB278 was ligated into similarly digested pGEM/54 creating pGEM/54Phe. In pGEM/54-Phe, the prokaryotic Phe resistance gene is in the same orientation as that of the sense 54-kDa fragment. In a third step, a blunt HindIII-EcoRI fragment from pT3T7/54kDa was introduced into SmaI and EcoRI sites of pGEM/54-Phe, upstream of the Phe gene, and with opposite orientation in respect to the PMMoV 54-kDa sequence originally present in the vector. The resulting plasmid, pGEM/IR 54, contains the antibiotic resistance gene between the antisense and the sense orientations of the PMMoV 54-kDa sequence. The entire hairpin RNA was inserted into the SacI site of pBI121 (Clontech, Madrid, Spain) just downstream of the GUS reporter gene, to create pBI/GusIR 54 (Fig. 1). This plant binary vector is under the transcriptional control of the $35 \mathrm{~S}$ promoter of CaMV and the $3^{\prime}$ end of the nopaline synthase. The GUS gene was excised from $\mathrm{pBI} / \mathrm{GusIR} 54$ by partial digestion with SacI and SmaI to create pBI/IR 54. The pGEM/54-Phe clone was digested with $S a c \mathrm{I}$, and the resulting $1.5-\mathrm{kb}$ fragment was inserted into the corresponding site of pBI121, recovering recombinant clones with two copies of the PMMoV 54-kDa Phe fragment arranged as head-to-head repeats in the sense (pBI/Gus[+]ssRNA 54) or antisense (pBI/Gus[-]ssRNA 54) orientation (Fig. 1). Structure of each cloned construct was verified by a combination of restriction mapping and Northern blot hybridization. Each of these constructs containing PMMoV 54-kDa sequences was transferred to A. tumefaciens strain LBA 4404 (T-DNA transfer-competent, Vir+) by direct transformation (An et al. 1988). pBI/GusIR 54 was also introduced into A. tumefaciens $\mathrm{C} 58 \mathrm{C} 1^{\mathrm{D}}$, a T-DNA transfer-defective strain (Vir-). The IR DNA constructs were stable in both $E$. coli DH5 $\alpha$ and $A$. tumefaciens strains, presumably as a result of the positive selection conferred by the Phe resistance gene.

The complete HC-Pro coding sequence (nucleotides 1,068 to 2,444 of the PPV sequence; Laín et al. 1989) of PPV 5.15 (López-Moya et al. 1994) was modified using polymerase chain reaction $(\mathrm{PCR})$ to introduce in-frame translational start and stop codons and was inserted between the CaMV $35 \mathrm{~S}$ promoter and the GUS gene sequence in pBI121, producing pBI-HCT (D. Barajas, unpublished data). This construct was designed to yield an mRNA in plants comprising the full-length HC-Pro sequence fused at the $3^{\prime}$ terminus to the GUS sequence, whereas only the HC-Pro sequence would be translatable. This inserted HC-Pro sequence was rendered noncoding in $\mathrm{pBI} / \mathrm{HCNT}$ by replacing the translation start codon ATG with two termination codons. The PVX vector (pP2C2S) used to clone the PMMoV 54-kDa gene sequence has been described previously (Baulcombe et al. 1995). A cDNA fragment encoding the entire $54-\mathrm{kDa}$ open reading frame was PCR-amplified from p54-5 plasmid, using primers homologous to nucleotides 3,499 to 3,521 and complementary to nucleotides 4,888 to 4,908 of the PMMoV sequence (Tenllado et 
al. 1995). The PCR-amplified fragment was cloned in the T/A site of pGEM-T Easy cloning vector, to create pGEM/54. pGEM/54 was digested with EagI, and the resulting 1.4-kb fragment was inserted into the corresponding site of $\mathrm{pP} 2 \mathrm{C} 2 \mathrm{~S}$, recovering recombinant clones with the PMMoV 54-kDa gene in the sense orientation (PVX/54). All constructs were characterized by restriction enzyme digestion and sequence analysis.

\section{A. tumefaciens infiltration and virus inoculation.}

$N$. benthamiana leaves were infiltrated with A. tumefaciens as described (Tenllado and Díaz-Ruíz 2001). For coinfiltration, equal volumes of cultures (optical density at $600 \mathrm{~nm}=0.8$ ) were mixed prior to injection. The origin of TMV-U1, the Spanish, and the Italian strains of PMMoV has been reported (García-Luque et al. 1993). The Leiden strain of AMV (Bol 1999) was maintained in $N$. benthamiana by mechanical inoculation. Infiltrated leaves of $N$. benthamiana plants were inoculated with either each of the different purified tobamoviruses (10 $\mu \mathrm{g}$ of PMMoV-S or PMMoV-I per ml or $5 \mu \mathrm{g}$ of TMV-U1 per ml) (Alonso et al. 1991) or with a 1:5 dilution of plant sap from AMV-infected $N$. benthamiana plants. Plant sap from the inoculated leaves of $N$. benthamiana plants was diluted 1:1000

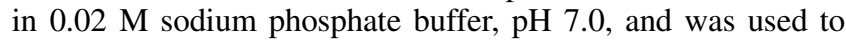
back-inoculate $N$. tabacum cv. Xanthi nc. In vitro transcription to produce infectious PVX and PVX derivative RNAs from template plasmids linearized with $S p h \mathrm{I}$ was performed as described (Chapman et al. 1992). Inoculation of plants was done on two fully expanded leaves by gently rubbing the leaf surface with the inoculum using carborundum as an abrasive. The inoculated plants were kept in growth chambers with a $16 \mathrm{~h}$ light and $8 \mathrm{~h}$ dark cycle at $25^{\circ} \mathrm{C}$, and the development of viral infection symptoms was monitored for as long as their life cycles.

\section{Analysis of viral RNA in plants.}

Total RNA was extracted from inoculated leaves at 7 dpi and from upper leaves 7 to $20 \mathrm{dpi}$ as described (Logemann et al. 1987). RNA samples (approximately $1 \mu \mathrm{g}$ ) were separated on 1 to $0.8 \%$ agarose formaldehyde gels and transferred to Hybond$\mathrm{N}$ membranes (Roche Molecular Biochemicals, Barcelona, Spain) by a low pressure vacuum system (VacuGene XL, Pharmacia, Uppsala, Sweden). Digoxigenin (DIG)-labeled riboprobes (Roche Molecular Biochemicals) were used to detect the respective viruses. PMMoV RNA was detected with a probe complementary to PMMoV nucleotides 3,411 to 4,388 that was transcribed from pT3T7/54kDa (Tenllado et al. 1995). AMV RNAs 3 and 4 were detected with a probe complementary to nucleotides 369 to 1,493 of AMV RNA 3 that was transcribed from pBluescript SK-/AMV-3 (Tenllado and Díaz-Ruíz 2001). PVX and PVX/54 RNAs were detected with a probe complementary to the 3' 720 terminal bases of PVX that was transcribed from StuI-linearized pP2C2S. Transient expression of A. tumefaciens transcripts was detected with a DIG-labeled riboprobe complementary to the GUS gene sequence that was transcribed from NcoI-linearized pGG5GUS (Simón-Buela et al. 1997). A hairpin structure for A. tumefaciens-expressed IR 54 was confirmed by resistance to RNase A under high salt conditions ( $0.3 \mathrm{M} \mathrm{NaCl}, 0.030 \mathrm{M}$ sodium citrate) and Northern blot hybridization, using a probe derived from pT3T7/54kDa.

Low molecular weight (LMW) RNA was isolated by anion exchange chromatography (RNA/DNA Midi Kit, Qiagen, Hilden, Germany) according to the manufacture's instructions described previously (Johansen and Carrington 2001), using 200 $\mu \mathrm{g}$ of total RNA derived from A. tumefaciens-injected leaves that were detached 4 days after infiltration. The LMW RNA $(20 \mu \mathrm{g})$ was separated by electrophoresis in a $15 \%$ polyacrylamide gel containing $7 \mathrm{M}$ urea and TBE (45 mM Tris-borate, $\mathrm{pH}$ 8.0, 1mM EDTA) buffer. Ethidium-bromide staining and visualization of the $5 \mathrm{~S}$ RNA/tRNA bands was used to monitor loading of RNA samples. The RNA in gels was transferred to Hybond-N membranes by capillary transfer according to standard procedures (Sambrook et al. 1989) and fixed by UV crosslinking (1,200 $\mu \mathrm{J}$, Stratalinker, Stratagene, Barcelona, Spain). Blots were prehybridized and hybridized using PerfectHybPlus buffer (Sigma, Madrid, Spain) at $38^{\circ} \mathrm{C}$. Radiolabeled DNA probes corresponding to the PMMoV 54-kDa sequence cloned in $\mathrm{pT} 3 \mathrm{~T} 7 / 54 \mathrm{kDa}$ were generated by random priming reactions in the presence of $\left[\alpha-{ }^{32} \mathrm{P}\right] \mathrm{dCTP}$. After $16 \mathrm{~h}$, blots were washed sequentially in $2 \times, 1 \times$, and $0.5 \times \mathrm{SSC}$ buffer plus $0.1 \%$ sodium dodecyl sulfate (SDS) $\left(20 \mathrm{~min}\right.$ each) at $50^{\circ} \mathrm{C}$.

\section{Immunoblot analysis.}

Tissue from agroinfiltrated and inoculated leaves was ground in liquid nitrogen and resuspended in two volumes of SDSpolyacrylamide gel electrophoresis (PAGE) sample buffer (Laemmli 1970). Protein samples were fractionated by electrophoresis on $10 \%$ (HC-Pro detection) or $12 \%$ (PMMoV CP detection) SDS-PAGE gels and were transferred to PVDF (polyvinylidene difluoride) membranes (Hybond-P; Amersham Biosciences, Buckinghamshire, U.K.) for immunoblot analysis. For PPV HC-Pro detection, blot membranes were probed, first, with a rabbit polyclonal antiserum against PPV HC-Pro and, second, with a goat anti-rabbit antibody conjugated with horseradish peroxidase (Nordic Immunology, Tilburg, The Netherlands). Detection was done with the ECL system (Amersham Biosciences). The polyclonal antiserum against PPV HC-Pro was produced by immunization of rabbits with purified HC-Pro protein expressed in E. coli (D. Barajas, unpublished data). For PMMoV CP detection, membranes were probed with a rabbit polyclonal antiserum against PMMoV (Alonso et al. 1989) and were subjected to the procedures described above.

\section{ACKNOWLEDGMENTS}

The kind gift of the clone containing the phleomycin resistance gene from J. C. Alonso (Centro Nacional de Biotecnología, CSIC) is acknowledged. We also thank J. C. Carrington (Oregon State University) for the generous gift of $A$. tumefaciens strain $\mathrm{C} 58 \mathrm{C} 1^{\mathrm{D}}$; J. A. García, (CNB, CSIC) for providing the clone pGG5GUS; S. Santa Cruz (Scottish Crop Research Institute) for providing the PVX vector; and B. Martinez-García (CIB, CSIC) for the polyclonal antiserum against PPV HC-Pro. D. B., M. V., P. G.-J., and F. A. A. were supported by doctoral fellowships from Comunidad de Madrid and MECD-FPU, CONICYT-BID (Chile), MECD-FPI (Spain), and CONICET (Argentina), respectively. F. T. is a recipient of a contract from CSIC (Spain). This work was supported by grants BIO2000-1605-C02 and BIO2000-0914 from CICYT (MCyT) and 07M/0123/2000 from Comunidad de Madrid.

\section{LITERATURE CITED}

Alonso, E., García-Luque, I., Avila-Rincón, M. J., Wicke, B., Serra, M. T., and Díaz-Ruíz, J. R. 1989. A tobamovirus causing heavy losses in protected pepper crops in Spain. J. Phytopathol. 125:67-76.

Alonso, E., García-Luque, I., de la Cruz, A., Wicke, B., Avila-Rincón, M. J., Serra, M. T., Castresana, C., and Díaz-Ruíz, J. R. 1991. Nucleotide sequence of the genomic RNA of pepper mild mottle virus, a resistance-breaking tobamovirus in pepper. J. Gen. Virol. 72:2875-2884.

An, G., Ebert, P. R., Mitra, A., and Ha, S. B. 1988. Binary vectors. A3. Pages 1-19 in: Plant Molecular Biology Manual. S. B. Gelvin and R. A. Schilperrot, eds. Kluwer Academic Publishers, Dordrecht, The Netherlands.

Anandalakshmi R., Pruss G. J., Ge X., Marathe R., Mallory A. C., Smith T. H., and Vance V. B. 1998. A viral suppressor of gene silencing in plants. Proc. Natl. Acad. Sci. U.S.A. 95:13079-13084.

Baulcombe. D. C., Chapman, S., and Santa-Cruz, S. 1995. Jellyfish green fluorescent protein as a reporter for virus infections. Plant J. 7:10451053

Béclin, C., Boutet, S., Waterhouse, P., and Vaucheret, H. 2002. A branched pathway for transgene-induced RNA silencing in plants. Curr. Biol. 12:684-688. 
Bernstein, E., Caudy, A. A., Hammond, S. M., and Hannon, G. J. 2001. Role for a bidentate ribonuclease in the initiation step of RNA interference. Nature 409:363-366.

Bol, J. F. 1999. Alfalfa mosaic virus and ilarviruses: Involvement of coat protein in multiple steps of the replication cycle. J. Gen. Virol. 80:1089-1102.

Bravo, A., and Alonso, J. C. 1990. The generation of concatemeric plasmid DNA in Bacillus subtilis as a consequence of bacteriophage SPP1 infection. Nucleic Acids Res. 18:4651-4657.

Brigneti G., Voinnet, O., Li, W. X., Ji, L. H., Ding, S. W., and Baulcombe D. C. 1998. Viral pathogenicity determinants are suppressors of transgene silencing in Nicotiana benthamiana. EMBO (Eur. Mol. Biol. Organ.) J. 17:6739-6746.

Catalanotto, C., Azzalin, G., Macino, G., and Cogoni, C. 2002. Involvement of small RNAs and role of the qde genes in the gene silencing pathway in Neurospora. Genes Dev. 16:790-795.

Chapman, S., Kavanagh, T., and Baulcombe, D. C. 1992. Potato virus X as a vector for gene expression in plants. Plant J. 2:549-557.

Chuang, C.-F., and Meyerowitz, E. M. 2000. Specific and heritable genetic interference by double-stranded RNA in Arabidopsis thaliana. Proc. Natl. Acad. Sci. U.S.A. 97:4985-4990.

Collins, J. 1981. Instability of palindromic DNA in Escherichia coli. Cold Spring Harbor Symp. Quant. Biol. 45:409-416.

Dalmay, T., Hamilton, A., Rudd, S., Angell, S., and Baulcombe, D. C. 2000. An RNA-dependent RNA polymerase in Arabidopsis is required for posttranscriptional gene silencing mediated by a transgene but not by a virus. Cell 101:543-553.

English, J. J., Mueller, E., and Baulcombe, D. C. 1996. Suppression of virus accumulation in transgenic plants exhibiting silencing of nuclear genes. Plant Cell 8:179-188.

Fire, A., Xu, S., Montgomery, M. K., Kostas, S. A., Driver, S. E. and Mello, C. C. 1998. Potent and specific genetic interference by doublestranded RNA in Caenorhabditis elegans. Nature 391:806-811.

García-Luque, I., Ferrero, M. L., Rodríguez, J. M., Alonso, E., de la Cruz, A., Sanz, A. I., Vaquero, C., Serra, M. T., and Díaz-Ruíz, J. R. 1993. The nucleotide sequence of the coat protein genes and $3^{\prime}$ noncoding regions of two resistance-breaking tobamoviruses in pepper shows that they are different viruses. Arch. Virol. 131:75-88.

Hamilton, A. J., and Baulcombe, D. C. 1999. A species of small antisense RNA in posttranscriptional gene silencing in plants. Science 286:950952

Hammond, S., Bernstein, E., Beach, D., and Hannon, G. 2000. An RNAdirected nuclease mediates post-transcriptional gene silencing in Drosophila cells. Nature 404:293-296.

Hammond, S. M., Caudy, A. A., and Hannon, G. J. 2001. Post-transcriptional gene silencing by double-stranded RNA. Nat. Rev. Genet. 2:110-119.

Johansen, L. K., and Carrington, J. C. 2001. Silencing on the spot. Induction and suppression of RNA silencing in the Agrobacterium-mediated transient expression system. Plant Physiol. 126:930-938.

Jorgensen, R. A., Atkinson, R. G., Forster, R. L., and Lucas, W. J. 1998. An RNA-based information superhighway in plants. Science 279:1486-1487.

Kasschau, K. D., and Carrington, J. C. 1998. A counterdefensive strategy of plant viruses: Suppression of posttranscriptional gene silencing. Cell 95:461-470.

Kasschau, K. D., and Carrington, J. C. 2001. Long-distance movement and replication maintenance functions correlate with silencing suppression activity of potyviral HC-Pro. Virology 285:71-81.

Laemmli, U. K. 1970. Cleavage of structural proteins during the assembly of the head of bacteriophage T4. Nature 227:680-685.

Laín, S., Riechmann, J. L., and García, J. A. 1989. The complete nucleotide sequence of plum pox potyvirus RNA. Virus Res. 13:157-172.

Lipardi, C., Wei, Q., and Paterson, B. M. 2001. RNAi as random degradative PCR: siRNA primer convert mRNA into dsRNAs that are degraded to generate new siRNAs. Cell 107:297-307.

Llave, C., Kasschau, K. D., and Carrington, J. C. 2000. Virus-encoded suppressor of posttranscriptional gene silencing targets a maintenance step in the silencing pathway. Proc. Natl. Acad. Sci. U.S.A. 97:1340113406.

Logemann, J., Schell, J., and Willmitzer, L. 1987. Improved method for the isolation of RNA from plant tissue. Anal. Biochem. 163:16-20.

López-Moya, J. J., Canto, T., López-Abella, D., and Díaz-Ruíz, J. R. 1994. Differentiation of Mediterranean plum pox virus isolates by coat protein analysis. Plant Pathol. 43:164-171.

Mlotshwa, S., Voinnet, O., Mette, M. F., Matzke, M., Vaucheret, H., Ding, S. W. Pruss, G., and Vance, V. B. 2002. RNA silencing and the mobile silencing signal. Plant Cell S289-S301.

Palukaitis, P., and Zaitlin, M. 1986. Tobacco mosaic virus. Infectivity and replication. Pages 105-131 in: The Plant Viruses, Vol 2. The RodShaped Plant Viruses. M. H. V. Van Regenmortel and H. FraenkelConrat, eds. Plenum Press, New York.

Palauqui, J. C., Elmayan, T., Pollien, J. M., and Vaucheret, H. 1997. Systemic acquired silencing: Transgene-specific post-transcriptional silencing is transmitted by grafting from silenced stocks to non-silenced scions. EMBO (Eur. Mol. Biol. Organ.) J. 16:4738-4745.

Palauqui, J.-C., and Balzergue, S. 1999. Activation of systemic acquired silencing by localised introduction of DNA. Curr. Biol. 9:59-66.

Rojas, M. R., Murillo, F., Allison, R. F., Gilbertson, R. L., and Lucas, W. J. 1997. Capsid protein and helper component-proteinase function as potyvirus cell-to-cell movement proteins. Virology 237:283-295.

Sáenz, P., Salvador, B. Simón-Mateo, C., Kasschau, K. D., Carrington, J. C., and García, J. A. 2002. Host-specific involvement of the HC protein in the long-distance movement of potyviruses. J. Virol. 76:19221930

Sambrook, J., Fritsch, E. F., and Maniatis, T. 1989. Molecular Cloning: A Laboratory Manual. Cold Spring Harbor Laboratory Press, Cold Spring Harbor, NY, U.S.A

Schöb, H., Kunz, C., and Meins, F. 1997. Silencing of transgenes introduced into leaves by agroinfiltration: A simple, rapid method for investigating sequence requirements for gene silencing. Mol. Gen. Genet. 256:581-585.

Schweizer, P., Pokorny, J., Schulze-Lefert, P. and Dudler, R. 2000. Double-stranded RNA interferes with gene function at the single-cell level in cereals. Plant J. 24:895-903.

Sijen, T., and Kooter, J. M. 2000. Post-transcriptional gene-silencing: RNAs on the attack or on the defense? Bioessays 22:520-531.

Simón-Buela, L., Guo, H. S., and García, J. A. 1997. Cap-independent leaky scanning as the mechanism of translation initiation of a plant viral genomic RNA. J. Gen. Virol. 78:2691-2699.

Smith, N. A., Singh, S. P., Wang, M. B., Stoutjesdijk, P., Green, A., and Waterhouse, P. M. 2000. Total silencing by intron-spliced hairpin RNA. Nature 407:319-320.

Sonti, R. V., Chiurazzi, M., Wong, D., Davies, C. S., Harlow, G. R., Mount, D. W., and Signer, E. R. 1995. Arabidopsis mutants deficient in T-DNA integration. Proc. Natl. Acad. Sci. U.S.A. 92:11786-11790.

Szittya, G., Molnár, A., Silhavy, D., Hornyik, C., and Burgýan, J. 2002. Short defective interfering RNAs of tombusvirus are not targeted but trigger post-transcriptional gene silencing against their helper virus. Plant Cell 14:359-372

Tenllado, F., and Díaz-Ruíz, J. R. 2001. Double-stranded RNA-mediated interference with plant virus infection. J. Virol. 75:12288-12297.

Tenllado, F., García-Luque, I., Serra, M. T., and Díaz-Ruíz, J. R. 1995. Nicotiana benthamiana plants transformed with the 54-kDa region of the pepper mild mottle tobamovirus replicase gene exhibit two types of resistance responses against viral infection. Virology 211:170-183.

Voinnet, O. 2001. RNA silencing as a plant immune system against viruses. Trends Genet. 17:449-459.

Voinnet, O., Pinto, Y. M., and Baulcombe, D. C. 1999. Suppression of gene silencing: A general strategy used by diverse DNA and RNA viruses of plants. Proc. Natl. Acad. Sci. U.S.A. 96:14147-14152.

Voinnet, O., Lederer, C., and Baulcombe, D. C. 2000. A viral movement protein prevents spread of the gene silencing signal in Nicotiana benthamiana. Cell 103:157-167.

Waterhouse, P., Graham, M. and Wang, M.-B. 1998. Virus resistance and gene silencing in plants can be induced by simultaneous expression of sense and antisense RNA. Proc. Natl. Acad. Sci. U.S.A. 95:1395913964.

Waterhouse, P. M., Wang, M. B., and Lough, T. 2001. Gene silencing as an adaptive defense against viruses. Nature 411:834-842.

Zamore, P. 2002. Ancient pathways programmed by small RNAs. Science 296:1265-1269. 